\title{
A Escola de Salamanca e a sua herança humanista para o direito internacional público: um estudo sobre as contribuições de Francisco de Vitória e Francisco Suárez
}

\author{
The School of Salamanca and its humanistic heritage for public international law: a study on \\ the contributions of Francisco de Vitoria and Francisco Suárez.
}

Caroline Figueiredo Lima*

Sandro Simões ${ }^{* *}$

\section{REFERÊNCIA}

LIMA, Caroline Figueiredo; SIMÕES, Sandro. A Escola de Salamanca e a sua herança humanista para o direito internacional público: um estudo sobre as contribuições de Francisco de Vitória e Francisco Suárez. Revista da Faculdade de Direito da UFRGS, Porto Alegre, n. 41, p. 54-69, dez. 2019. DOI: <https://doi.org/10.22456/0104-6594.99253>.

\begin{abstract}
RESUMO
Os problemas atuais que o Direito Internacional enfrenta possuem relação direta com os pontos que pertencem a uma compreensão primordial sobre a formação do conceito de comunidade universal. Dessa forma, cabe salientar que tais questões têm profunda relevância no pensamento dos grandes mestres da Escola Ibérica da Paz, no séc. XVI e XVII. O presente artigo tem por objetivo apresentar alguns dos estudos produzidos pela Escola de Salamanca, em especial, as contribuições de Francisco de Vitoria e Francisco Suárez, realizados durante este período. Através de uma metodologia bibliográfica e tendo como fio condutor a Opinião Consultiva $n^{\circ}$ 16/1999 da Corte Interamericana de Direitos Humanos, visa investigar a criação do Direito Internacional Público, questão candente destes estudiosos. Ainda procura-se analisar as principais contribuições conceituais aportadas pela Escola de Salamanca como fundamentação para o desenvolvimento da paz e justiça entre as nações, por meio de confrontações das noções de razão da humanidade e razão do Estado, com vias à compreensão da comunidade universal. Como resultado, concluiu-se que o resgate dos estudos tomistas, aliados ao movimento da Igreja em revisar alguns costumes antes criticados por Lutero e pelo humanismo da baixa Idade Média, trouxeram grandes contribuições para a renovação do Direito das Gentes (posteriormente considerado nas suas relações com os Direitos Humanos) e para a constituição de uma comunidade internacional enraizada em outro fundamento que não a razão do Estado.
\end{abstract}

\section{PALAVRAS-CHAVE}

Direito Internacional; Escola Ibérica; Comunidade universal; Opinião Consultiva nº 16/1999.

\begin{abstract}
The current problems faced by international law have direct relation with the points that belong to a primordial understanding on the formation of the concept of universal community. Thus, it is important to point out that such questions have profound relevance in the thinking of the great masters of the Iberian School of Peace $\left(16^{\text {th }}\right.$ and $17^{\text {th }}$ centuries). This article aims to present some of the studies produced by the School of Salamanca, especially the contributions of Francisco de Vitoria and Francisco Suárez during this period. Through a bibliographic methodology and guided by the Advisory Opinion No. 16/1999 of the Inter-American Court of Human Rights, the article aims to investigate the creation of public international law, an issue looked upon by these scholars, and seeks to analyze the main conceptual contributions provided by the School of Salamanca as the foundation for the development of peace and justice between nations, through the confrontation of the notions of reason of humanity and reason of State, with the objective of understanding the universal community. As a result, it was concluded that the rescue of Thomistic studies, allied with the Catholic movement towards
\end{abstract}

\footnotetext{
* Aluna do Mestrado em Direitos Fundamentais, Políticas Públicas e Desenvolvimento, do Centro Universitário do Pará (CESUPA). Bacharel em Direito pelo CESUPA.

** Professor Assistente Convidado da Faculdade de Direito da Universidade de Lisboa (Instituto de Teoria e História do Direito-THD). Professor do Centro Universitário do Pará (CESUPA). Doutor em Direito pela Università del Salento, Lecce.
} 
revising some customs previously criticized by Luther and the humanists of the Late Middle Ages, made major contributions to the renewal of the Law of the People (later considered in their relations with Human Rights) and to the constitution of an international community rooted in a foundation other than the reason of State.

\section{KEYWORDS}

International Law; Iberian School; Universal community; Advisory Opinion No. 16/1999.

\section{SUMÁRIO}

1. Introdução. 2. Escola Ibérica da Paz: breve contexto histórico e os problemas candentes de seu tempo. 3. Francisco de Vitória e Francisco Suárez: a formação do direito internacional público. 4. Conclusão. Referências. Dados da publicação.

\section{INTRODUÇÃO}

Para a compreensão do Direito Internacional Público, bem como de seus desdobramentos práticos, é fundamental compreender quais são as suas raízes de fato. Dessa forma, a partir de uma metodologia bibliográfica, o presente estudo visa investigar a seguinte questão: quais foram as principais contribuições realizadas por Francisco de Vitória e Francisco Suárez, para a formação do conceito de Comunidade Universal?

Tal ponto reflete uma real necessidade de resgatar os estudos basilares destes filósofos, principalmente em um momento em que a soberania tem se apresentado como um dos pontos mais candentes do século presente. Por esse motivo, também é feito um panorama sobre a Opinião Consultiva no 16/1999 da Corte Interamericana de Direitos Humanos, onde são trabalhados os direitos dos indivíduos exilados a partir dos marcos primordialmente analisados pela Escola de Salamanca.

A fim de melhor assimilação das ideias apresentadas, é preciso conceber que o conceito de comunidade universal ${ }^{1}$ tem seu fundamento no Direito Natural. Dito de outra forma, tem como pilar o fato de que a vontade dos Estados não mais interessa para o seu advento, cedendo lugar para que os Estados estejam sujeitos a direitos e deveres em virtude do ius communicationis.

Neste diapasão, remonta-se ao paradigma da Razão do Estado e Razão da Humanidade. A primeira, aquela correspondente ao que posteriormente seria denominado de positivismo jurídico. Assim, o que transforma o fato bruto em jurídico não é sua facticidade,

\footnotetext{
${ }^{1}$ A utilização do termo "comunidade universal", é feita com base na tese de Pedro Calafate (2017, p. 51), quando afirma que a Escola Ibérica visava "um conceito de comunidade não meramente internacional, mas propriamente universal, com base numa ordem que não radicava na estrita vontade dos estados nem era por eles voluntariamente criada". Ou seja, uma organização que questionada pela necessidade de ratificação de compromissos internacionais, para enfim, possuir direitos e deveres dentro da comunidade.
} 
seu pertencimento ao âmbito da natureza, mas o sentido que se liga a esse ato, a significação que $\mathrm{o}$ ato possui.

Ou seja, o simples evento, enquanto elemento da natureza pertencente ao âmbito de fatos meramente brutos, não constitui esse episódio, objeto do conhecimento jurídico. Este modo de pensar gera ainda uma série de objeções apontadas pelos grandes mestres da Escola de Salamanca: em seu lugar, uma nova forma de refletir o Direito e a condição humana ganham espaço com a Razão da Humanidade.

Francisco de Vitoria, um dos mestres da Escola de Salamanca, forneceu grandes contribuições para o advento do Direito Internacional dos Direitos Humanos. Tal como é trabalhado ao longo do presente estudo, o ius gentium tem por base uma retomada das teorias de Tomás de Aquino.

Destarte, o primeiro capítulo tem por objetivo apresentar e contextualizar esse período de produção de conhecimento, a fim de situar o problema que os estudiosos enfrentavam naquele momento e como o compreendiam. Além disso, busca mostrar conceitos importantes que foram trabalhados anteriormente por Tomás de Aquino.

O segundo capítulo, por sua vez, é um aprofundamento de seu antecessor, e aponta enfaticamente para a Escola de Salamanca, principalmente para as contribuições de Francisco de Vitória e Francisco Suárez. Assim, é possível expor com maior clareza sua herança para o Direito Internacional Público.

\section{ESCOLA IBÉRICA DA PAZ: BREVE CONTEXTO HISTÓRICO E OS PROBLEMAS CANDENTES DE SEU TEMPO}

Pensar a fundamentação ética dos Direitos Humanos importa investigar as raízes históricas que ensejaram em seu aprofundamento. Dessa forma, é possível afirmar que, por volta dos séculos XVI e XVII, Portugal e Espanha tiveram um florescimento no que tange aos estudos que hoje se entende como sendo o processo de internacionalização dos Direitos Humanos.

Esse período foi marcado pelo processo da Contrarreforma ou Reforma Católica, no qual os teólogos começaram a organizar-se em seminários e universidades para o estudo da teologia e sua defesa racional. Também foi nesse contexto que a Companhia de Jesus foi criada, tendo como um de seus expoentes Francisco Suárez (que continuou seus estudos nas Universidades de Salamanca e Coimbra). 
A concepção voluntarista de formação do Direito Internacional, neste contexto, é totalmente negada. Em linhas gerais, tal fato se deve à recusa de compreender as normas apenas à luz de sua validade, desconsiderando parâmetros morais que devem nortear o ordenamento jurídico.

Além desse posicionamento, a tese normativista de compreensão do Direito Internacional se aproxima dos estudos kelsenianos, segundo os quais Estado e Direito encontram um ponto de convergência tanto na ordem interna, quanto no plano internacional, fazendo parte, contudo, de um sistema hermeticamente fechado, que não reconhece elemento qualquer fora desse contexto.

Em outras palavras, compreender que os Estados estão obrigados apenas com relação aos acordos e tratados voluntariamente aceitos, ou acordos tacitamente firmados entre si, impede um aprofundamento no que tange às questões da dignidade da pessoa humana, uma vez que a coloca em um patamar de disponibilidade ao arbítrio do Estado.

Em contraponto direto a esta corrente, Francisco de Vitória aduz que "Tudo o que decorre de princípios naturais que conclui com grande probabilidade é independente da vontade. É, portanto, moralmente necessário e consequentemente natural"2 (VICENTE, 1952, p. 615). Ou seja, independe de uma validação dos Estados para existirem, pois são consequências lógicas da condição humana.

Estes pensamentos, portanto, estão inseridos no que se pode compreender como o sistema de fundamentação do Direito Internacional. Contrapondo-se aos estudos supracitados, tem-se ainda uma terceira corrente, compreendida como pertencente ao sistema jusnaturalista, pautada pelo Direito Natural e aprofundada através dos estudos de Tomás de Aquino, conforme analisado mais adiante.

Então, como definir o Direito Natural? Luciano Pereña Vicente destaca as três classes de princípios utilizadas por Francisco de Vitória. Em suma, suas principais características são: a autoevidência, a decorrência lógica um do outro, e "o que se deduz em boa consequência moral dos princípios moralmente conhecidos"3 (VICENTE, 1952, p. 615).

Em um primeiro olhar, é clara a recusa em reduzir a Justiça a parâmetros de validade ou eficácia. Partir da premissa de que todos os indivíduos estão estreitamente conectados em virtude de sua racionalidade não exige que tal seja reconhecido pelas fontes sociais, mas ainda assim implica nos devidos desdobramentos lógicos de tal raciocínio.

\footnotetext{
${ }^{2}$ Texto original: "Todo lo que se sigue de principios naturales que concluye con gran probabilidad, es independiente de la voluntad. Es por lo tanto moralmente necesario y en consecuencia natural".

${ }^{3}$ Texto original: "lo que se deduce en buena consecuencia moral de principios moralmente conocidos".
} 
Afirmar que é Direito Natural o que é conhecido por todos evidencia a forte influência tomista nos estudos de Vitória. A razão ôntica, aqui, retorna para analisar a natureza e o intelecto; e aponta, mais tarde, em uma separação conceitual entre a consistência dos princípios naturais e o Direito das Gentes como uma forma de Direito Positivo, este sim, com fundamento na vontade humana (VICENTE, 1952, p. 617).

Assim, com base no conjunto desses critérios, é possível identificar que Vitória não pode admitir a tese voluntarista de formação do Direito Internacional, tampouco normativista, por ir contra os fundamentos naturais. Portanto, como teólogo e filósofo que se preocupou com as questões dos nativos do "Novo Mundo", "ele avalia e formula os direitos e deveres dos índios, por exemplo, examinando seus rituais, costumes e modos de vida. [... Elaborou um sistema] para as relações entre as sociedades que ele entendeu pertencer a duas ordens culturais muito diferentes"4 (ANGHIE, 1996, p. 322).

Francisco Suárez também apresentou contribuições neste sentido, pois, para ele, a formação do conceito de comunidade universal "era um postulado objetivo, traduzia uma ordem natural pensada fora do quadro da concepção individualista dos estados, [...] indivíduos tomados isoladamente, desligados de uma ordem mais vasta sem consideração da função que nela deveriam desempenhar" (CALAFATE, 2017, p. 51).

Ou seja, a capacidade de os indivíduos se relacionarem, exercendo tal sociabilidade, encontra no filósofo uma relação intrínseca com o Direito Natural comum em nível universal. Estas anotações são de essencial relevância para a própria concepção de Direito, e tiveram acentuado impacto no pensamento da época.

A compreensão aqui é de uma ordem não apenas internacional, mas universal, que, desvinculada do Papa ou Imperador, na Baixa Idade Média, trabalha concepções que visam uma ligação de solidariedade entre os Estados, anterior ao jus gentium (CALAFATE, 2017, p. $51)$.

As Escolas de Coimbra, Lisboa, Évora, Salamanca, dentre outras, tiveram uma profunda relevância para o que hoje, em conjunto, denomina-se de "Escola Ibérica da Paz". É possível afirmar que as contribuições feitas pelos pensadores egressos dessas escolas possuem em comum a retomada dos estudos de Tomás de Aquino (VICENTE, 1952, p. 12) e Aristóteles.

\footnotetext{
${ }^{4}$ Texto original: "He assesses and formulates the rights and duties of the Indians, for example, by examining their rituals and customs and ways of life. [...] for relations between societies which he understood to belong to two very different cultural orders".
} 
A teologia escolástica, em um duro momento de críticas tanto oriundas de Lutero quanto do humanismo, passou por algumas modificações a partir das escolas de formação eclesiástica. Eram tangíveis as inquietações de teólogos com profunda preocupação sobre as questões da compreensão da natureza humana e da delimitação da soberania do povo.

Esse contexto de reflexão sobre o atual panorama da Igreja fez com que estes pensadores realizassem estudos a fim de que fossem esclarecidos como os poderes político e civil deveriam ser exercidos (CALAFATE, 2014, p. 81), e ato contínuo, a proteção dos indivíduos fosse garantida.

Juan Plans (2000, p. 207), aponta para duas opções que se apresentavam nessa circunstância: abandonar por completo toda a tradição anterior existente, a partir de uma renovação da teologia em todos os seus aspectos; ou empreender uma revisão a fundo dos problemas que enfrentava, conservando-a parcialmente, mas ao mesmo tempo incorporando novos pensamentos.

O segundo caminho foi apontado como o escolhido pelos teólogos com formação nas escolas da Península Ibérica. E, neste sentido, os novos aportes são notadamente marcados em dois estágios de reflexão: positivo e negativo. Positivo, ao incorporar novos enfoques e valores, e negativo, ao adotar uma postura de revisão dos defeitos e maus costumes que foram cultivados ao longo do tempo.

Para tanto, foram utilizados os textos de Tomás de Aquino, que, conforme será melhor elucidado adiante, não foi o único pensador a influenciar este novo momento da teologia, mas certamente um dos principais expoentes. A Suma Teológica (Summa Theologiae), adotada como uma espécie de texto universitário por estes estudiosos, dentre as suas contribuições mais basilares, exibe a atribuição do caráter científico, rigor científico e metodológico na separação entre o divino e o terreno/temporal.

Dessa forma, cabe realizar um breve comentário sobre a divisão quadripartite de Tomás de Aquino e expor de que forma ela inspirou os trabalhos realizados por Vitória e por Suárez. Em um esforço de estabelecer uma separação entre fé e ciência, a lei foi separada em quatro partes: lei eterna, lei divina, lei natural e lei humana.

A primeira corresponde a uma ordem que existe em todo universo, uma lei estabelecida pelo Deus Criador segundo a fé cristã. Assim sendo, o homem não é capaz de compreendê-la; não está sujeita ao tempo, ou sequer é produto de uma razão humana. 
Por outro lado, a lei divina, é aquela que foi dada (revelada) aos homens, através das escrituras. Ou seja, refere-se às normas e ritos eclesiásticos dados por Deus aos indivíduos, tais como os atos de batismo e remissão de pecados, praticados pela Igreja Cristã.

As duas leis supracitadas e brevemente explanadas não constituem objeto de estudo ou investigação do Direito em si. Fazem, portanto, referência tão somente a questões que refletem os aspectos da fé na vida das pessoas. Importante frisar esta informação, a fim de que tais conceitos não sejam confundidos entre si.

A lei natural, por sua vez, representa o conhecimento racional do bem. Em outras palavras,

Tomás de Aquino considera também o bem comum, um elemento vital do pensamento da lei natural que influenciou fortemente Vitoria [...] A razão, também como preocupação crucial para os neoescolásticos como Vitoria, continua a desempenhar um papel importante na teoria jurídica e prática. ${ }^{5}$ (ARAUJO, 2012, p. 323-324)

E, por fim, tem-se as leis humanas, consolidadas pelo Estado, e que devem retratar o que a lei natural afirma. Ou seja, devem refletir os preceitos naturais, e apenas confirmá-los. Calafate (2017, p. 55) assevera que "Para Suárez, não cumpria ao jurista observar a prática dos estados, mas dizer qual é o direito!”.

Mas então, como essa renovação, de cunho teológico e filosófico, foi tão fundamental para a compreensão do Direito Internacional, e poder civil e político? Em primeiro lugar, pode-se verificar como a noção de dignidade transcende a ordem jurídica. Ou seja, traz implicações para além dos deveres formais que são impostos pelo Estado.

A construção de todo esse resgate dos estudos tomistas, aliado ao olhar humanista de Vitoria e Suárez, traz reflexões de obrigações morais que não exigem a ingerência de um poder estatal.

A razão sempre busca o fim de todas as coisas, que é o bem. Ora, se tudo tende ao seu fim, temos que admitir que tudo tem uma mesma essência. $\mathrm{O}$ importante é mostrar o caminho e a diretriz ética que concretiza esse conceito tão caro ao Direito.

Assim, fica nítido com esses mestres o firmamento do conceito de dignidade humana, além dos pilares do Direito Internacional moderno, bem como da concepção de comunidade

\footnotetext{
${ }^{5}$ Texto original: "Aquinas also considers the common good - a vital element of the natural law thinking that strongly influenced de Vitoria [...] Reason also something of crucial concern to the Neo-Scholastics such as de Vitoria continues to play an important role in legal theory and practice".
} 
internacional, ou seja, "a contribuição para o processo de secularização que substituiu a ideia de cristandade com a da comunidade internacional"6 (LACAMBRA, 1948, p. 14).

Composta por professores e/ou egressos das universidades supracitadas, em sua maioria teólogos da tradição judaico-cristã, Francisco de Vitória, Francisco Suárez, Luís de Molina, dentre outros, são estudados no presente artigo por suas contribuições não somente ao Direito Internacional Público, mas na questão da ética humanista e universalizante.

No contexto da Reforma Católica, esses mestres observaram o período da colonização das Américas e o uso da força empregado aos nativos das respectivas regiões, e concluíram que os parâmetros da guerra justa não estavam sendo respeitados. Em outras palavras, careciase enormemente de um aprofundamento dos princípios filosóficos, jurídicos e teológicos que trabalhassem melhor os preceitos do que afirmavam ter origem no Direito Natural.

A escola de Évora (1593) já analisava a defesa dos cidadãos contra a tirania e a opressão. Ipsis litteris: "qualquer homem pode, por direito natural e sobretudo os príncipes, defender os inocentes da tirania e da opressão" (LUIS DE MOLINA apud CALAFATE, 2014, p. 92). Temas seriamente atuais, principalmente na realidade latino-americana.

Dessa forma, alguns autores sustentam que, no caso de Francisco de Vitoria, por exemplo, o que os preocupava não era exatamente se a Espanha agia corretamente ou não, mas as questões que refletiam o fundamento para tais ações. Em outras palavras "Quem é soberano? Quais são os poderes de um soberano? Os índios são soberanos? Quais são os direitos e deveres dos índios e dos espanhóis? Como os respectivos direitos e deveres dos espanhóis e dos índios devem ser decididos?"7 (ANGHIE, 1996, p. 322).

Ainda sem utilizar a terminologia "Direito Internacional Público", mas tecendo noções iniciais sobre uma comunidade internacional, foi amplamente questionado o predomínio da decisão papal na esfera política, além da origem da autoridade emanada pelo imperador e o poder laico.

O Papa, à luz de Francisco de Vitória, Francisco Suárez, entre outros, tinha poder limitado no que tange aos aspectos de governo, ou seja, questões sobre a esfera pública que não diziam respeito à ordem espiritual dos indivíduos. Claro que tal posicionamento não era unânime, encontrando em Álvaro Pais uma forte oposição.

\footnotetext{
${ }^{6}$ Texto original: "la contribución al proceso de laicización que ha sustituido la idea de la cristiandad por la de comunidad internacional".

${ }^{7}$ Texto original: "Who is sovereign? What are the powers of a sovereign? Are the Indians sovereign? What are the rights and duties of the Indians and the Spaniards? How are the respective rights and duties of the Spanish and the Indians to be decided?".
} 
Para Pais, o Papa, além de autoridade da igreja, era dominus orbis nas questões temporais (ou "mundanas") e espirituais. Nesse sentido, buscava justificar a ingerência do líder na "ética colonial de conquista e subjugação dos pagãos e gentios da América" (CALAFATE, 2014).

Sustentava, portanto, que este sacerdote detinha o poder político que lhe era incumbido por Deus, e consequentemente o imperador o recebia do Papa, e não do povo. Assim, em contraposição a essas formulações, os mestres da Escola Ibérica também trabalhavam a questão da secularização da Igreja. Por isso, tem-se "o problema de criar um sistema de direito que pudesse ser usado para explicar as relações entre sociedades que ele [Francisco de Vitória] entendia pertencer a duas ordens culturais muito diferentes, cada uma com suas próprias ideias de propriedade e governança", (ANGHIE, 1996, p.322).

Portanto, "a lei imperial não pode suprimir as providências naturais" (AZPILCUETA apud CALAFATE, 2014). Em outras palavras, “o Papa não pode dar o que não é dele; nem pode invocar autoridade própria, pois também a não tinha, em função do fundamento jusnaturalista do poder civil" (CALAFATE, 2014), posto que consideravam que da comunidade emanava o poder de constituição dos imperadores, e não de Deus diretamente. Assim, não depende de uma ordem jurídica imperial, mas do povo, através da razão natural.

Por esse motivo, os estudos apresentados por Tomás de Aquino são tão importantes para a construção da base destas escolas. A partir da separação entre a lei divina, a lei eterna, a lei natural e a lei humana, e em um momento em que a Igreja Católica buscava racionalizar e uniformizar a proteção aos indivíduos. Em outras palavras, buscava-se o bem comum dos seres humanos a partir da concepção objetiva de justiça universal, analisada pelo jusnaturalismo escolástico.

Em Madri, com o resgate do Corpus Hispanorum de Pace (publicado pela primeira vez apenas em 1987), um compilado dos principais estudos realizados por estes pensadores da Escola de Salamanca, a pesquisa nessa área foi reavivada. Dessa forma, ficaram ainda mais nítidas as questões que trabalhavam a ética e a teoria da lei natural, além de pontos sobre a filosofia política como o constitucionalismo moderno, soberania, etc.

Francisco de Vitória preocupa-se, portanto, principalmente com os elementos caracterizadores da guerra e com quando esta guerra seria legítima ou não. Para o pensador, uma guerra seria justa em duas hipóteses: legítima defesa ou sendo esta a última possibilidade

\footnotetext{
${ }^{8}$ Texto original: "the problem of creating a system of law which could be used to account for relations between societies which he understood to belong to two very different cultural orders, each with its own ideas of propriety and governance."
} 
para se alcançar a paz. Neste sentido, Suárez também se preocupava com a guerra justa, não conceituando diretamente a noção de um "Direito Internacional", mas discutindo questões preliminares.

Para uma guerra equânime, são trabalhados ainda pontos sobre a proporcionalidade dos meios empregados pelo Estado no momento da intervenção humanitária. Dessa forma, buscava-se evitar o "terrorismo do Estado", fato que, até os dias atuais, é amplamente utilizado no tocante aos estudos sobre o Direito de Guerra ou Direito Humanitário.

No caso de guerras injustas, por outro lado, uma das maiores contribuições da Escola Ibérica foi considerar a possibilidade da utilização da "desobediência civil". Ora, a partir do raciocínio de que uma lei deve ser moral para ser justa e aplicável, entendeu-se no caso inverso que era permitido, graças a princípios filosóficos, jurídicos e teológicos, seu descumprimento.

\section{FRANCISCO DE VITÓRIA E FRANCISCO SUÁREZ: A FORMAÇÃo dO DIREITO INTERNACIONAL PÚBLICO}

No apogeu do período das Grandes Navegações e descobrimentos, a Península Ibérica tinha na colonização um ponto de grande discussão e embate. Conforme explanado alhures, a partir desse momento foi preciso compreender como lidar com os nativos dessas regiões.

A euforia com a América e a crise europeia foram ambiente fértil para que Francisco de Vitoria se preocupasse de forma mais enfática com a questão da justiça e da moralidade. Assim, "os eventos universais que se seguem dão origem a teorias internacionais; e como a crise foi o conflito entre povos e civilizações, surge a tese de uma lei comum entre as nações"9 (VICENTE, 1952, p. 607).

Duas de suas principais lectures foram dedicadas a trabalhar o direito de guerra, principalmente tendo como plano de fundo a relação entre os espanhóis e indígenas. São elas "De Indis Noviter Inventis" e "De Jure Bellis Hispanorum in Barbaros".

A partir da retomada sobre a lei positiva trabalhada por Tomás de Aquino, e à luz do Direito Natural, tece estudos sobre a natureza do Direito das Gentes, sua origem e seus sujeitos. Assim, o Direito Internacional dos Direitos Humanos inicia propriamente a sua fundamentação.

\footnotetext{
${ }^{9}$ Texto original: "Los hechos universales que se suceden, dan lugar a teorías internacionales; y como la crisis era el conflicto entre pueblos y civilizaciones, surge la tesis de un derecho común entre naciones".
} 
Em primeiro lugar, quanto à natureza do direito das gentes, Vitoria inaugura o pensamento de que este direito, por si só, não possui em si uma razão de justiça. Em outras palavras, é preciso observar qual objeto está sendo ordenado por ele, e se o seu fim corresponde a este ideal.

Assim, "propter se non importat aequitatem, sed propter aliquid aliud" (VITORIA apud VICENTE, 1952, p. 613). A guerra, por exemplo, faz parte do Direito das Gentes. Contudo, nem sempre ela será injusta, visto que seu conteúdo não se exaure em si mesma. Ao atentar para a tese de Vitoria, é preciso observar os fins a que ela serve, se tem por escopo ser o único meio para alcançar a paz ${ }^{10}$.

Importante, ainda, não confundir dois institutos muito trabalhados neste ponto: o Direito Natural e o Direito das Gentes. Por vezes, é feita uma confusão entre ambos, dando a entender que correspondem ao mesmo sentido, que possuem o mesmo significado.

Francisco de Vitoria preocupou-se com essa questão e buscou esclarecer que, em verdade, não podem ser confundidos, pois nesse caso, o Direito das Gentes seria o próprio Direito Natural (dedução errônea). Como, então, elucidar estes conceitos?

Conforme explanado introdutoriamente, em linhas gerais o Direito Natural funciona como a razão sob a qual o Direito das Gentes é construído, ou seja, o "sistema de lei natural universal do ius gentium cujas regras podem ser determinadas pelo uso da razão"11 (ANGHIE, 1996, p. 325). Desse modo, são autoevidentes e comuns a todas as sociedades humanas.

Assim, aduz que “o Direito das Gentes como forma do Direito Positivo tem seu fundamento na vontade humana" $" 12$ (VICENTE, 1952, p. 617), no consenso universal entre os sujeitos. Além disso, tem como fim específico o bem de todos que estão conectados através o gênero humano.

Suárez nasce dois anos depois da morte de Vitoria. Por ter vivido um contexto de formação da Europa e nascimento do Estado Moderno, suas teorias são amplamente criticadas por alguns filósofos de matriz tomista. Para eles, o que de fato existe são duas linhas extremas que colocam Vitoria e Suárez em pontos distintos da linha internacionalista espanhola.

\footnotetext{
${ }^{10}$ Matéria do Direito Internacional Humanitário, o exercício de confronto armado é um ponto interessante para a compreensão da origem do ius gentium. Tal fato se deve à complexidade desse instituto e ao modo através do qual o filósofo desenvolve suas reflexões.

${ }^{11}$ Texto original: "universal natural law system of jus gentium whose rules may be ascertained by the use of reason".

${ }^{12}$ Texto original: "El derecho de gentes como forma de derecho positivo tiene su fundamento en la voluntad humana".
} 
Luis Lacambra afirma que "Suárez, em muitos pontos, complementa Vitoria; avança em outros, fica para trás em alguns. Em geral, age de modo independente, de forma alguma como um membro de uma escola"13 $(1948$, p. 15). Para o autor, Vitoria está mais próximo da Idade Média, ao contrário de Suárez; este, por sua vez, é um "homem da Contrarreforma", mas afirma que, apesar das críticas, as discrepâncias não são tão grandes assim.

Para tanto, foi invocada a questão do dever de consciência que os Estados devem ter (ou imperativos de consciência), além da inexistência da possibilidade de recusa a crueldades que ofendessem a dignidade do próximo.

Tal estudo possui reflexos altamente complexos nos dias atuais, especialmente no tocante às atrocidades nazistas ocorridas durante a Segunda Guerra Mundial. Um olhar atento para esse terror choca ao se perceber que toda desumanidade cometida foi realizada através de autorização das autoridades políticas da época.

Francisco de Vitoria é considerado, juntamente com Grotius (através de uma continuidade destes estudos anos mais tarde, na Holanda), um dos pais fundadores do Direito Internacional. Contudo, a partir de uma pesquisa apurada nos manuais e obras de Direito Internacional Público, em sua maioria é possível verificar que este marco é pouco ou nada exercitado no Brasil.

A Corte Interamericana de Direitos Humanos, órgão pertencente à Organização dos Estados Americanos - OEA, é um exemplo da aplicação do empenho realizado séculos antes pelas Escolas Ibéricas do Renascimento. Tal fato, ganha ainda maior realce nos votos realizados por seu então Presidente, Antônio Augusto Cançado Trindade.

Na Opinião Consultiva $N^{\circ} 16 / 1999$, ao discorrer sobre o devido processo legal e o direito de exilados contatarem seus respectivos consulados, um dos fundamentos utilizados para garantir este direito, foi a diferenciação da razão do Estado e razão da humanidade. Para o professor, não mais subsiste o "positivismo jurídico degenerado", que encontra no Estado o monopólio da titularidade de direitos.

Ao esclarecer a Convenção Americana de Direitos Humanos (CADH), afirma que, por mais que expressamente não existam disposições que garantam a assistência consular, através de um olhar humanista, e não meramente voluntarista, é possível encontrar guarida na garantia deste bem, qual seja, a justiça.

\footnotetext{
${ }^{13}$ Texto original: "Suárez, en muchos puntos, complementa a Vitoria, le avanza en otros, le queda rezagado en alguno. En general, procede con independencia, en modo alguno como miembro de una escuela".
} 
Por este motivo, "consagra as premissas de que os direitos humanos, inerentes a cada ser humano e inalienáveis, antecedem os direitos dos Estados; de que o poder estatal deriva da vontade do povo; e de que a justiça prima sobre o direito estatal positivo" (CANÇADO, 2003, p.35).

Nesse esforço intelectual, os estudos de Tomás de Aquino tiveram profunda relevância na sustentação de uma razão do Estado e da Razão da Humanidade, de forma que estas não se confundissem entre si. Em outras palavras, tal como aduz Suárez, é possível afirmar que não se trataria de uma "lei" das gentes, mas de um "direito" das gentes, não necessariamente positivado.

Essencial frisar que tal concordância entre os indivíduos está sob a égide de leis morais que são superiores ao Estado. Tal concepção talvez seja uma das principais ideias trabalhadas tanto por Vitoria, quanto por Suárez. Por esse motivo, a compreensão da unidade entre os seres humanos e o bem comum universal são pontos cruciais em ambas as teorias.

Para tanto, o ius communicationis tem fundamental relevância no entendimento da consistência dessas relações entre os povos. Formulado por Francisco de Vitoria, baseia-se na conexão de fraternidade e sociabilidade entre os povos, fato esse que gera vínculos humanos livres - não decorrentes de uma lei escrita propriamente dita.

Desse modo, Pedro Calafate faz uma observação no que tange ao estudo realizado por Suárez décadas depois. Para aquele, ao discorrer sobre a tese da soberania relativa dos Estados, considera que "dizer que a soberania dos estados é relativa e não absoluta significa que o soberano só tem poder para o que é justo e que para o que é injusto nenhum poder tem" (CALAFATE, 2017, p. 52).

Em De legibus (1612), leciona o fato de que os Estados, por pertencerem a uma comunidade universal, estão intrinsecamente ligados pelo gênero humano. Assim, tal como Vitoria, discorre sobre o Direito de Guerra e apura a indispensabilidade de terem na Razão a afirmação de que o combate "não era um meio natural de resolução de conflitos, afirmando a paz como caracterização da vida" (CALAFATE, 2017, p. 53).

Essa tese reflete a preocupação do filósofo com a concordância entre a soberania e o ius gentium. Encontrou a resposta para essa questão não nos Estados (em seu sentido organizacional), mas na limitação desse poder pelo Direito Natural. Ou seja, contrariou a tese do voluntarismo estatal ilimitado. A soberania é, portanto, relativa, pois somente encontra poder sob o que é justo. 


\section{CONCLUSÃO}

Com base no exposto, faz-se extremamente necessário um trabalho que resgate os estudos dos grandes mestres de Portugal e Espanha, bem como destaque suas contribuições ao que hoje denominamos de Direito Internacional. Com isso, o presente artigo possui por escopo articular os pensamentos destes pensadores e demonstrar sua relevância até os dias atuais.

O voluntarismo estatal foi amplamente criticado pelos pensadores da Escola Ibérica. Por ser a humanidade dotada de uma razão universal, não caberia aos Estados a firmação de tratados ou acordos que dispusessem sobre aspectos específicos de proteção, uma vez que tais direitos são autoevidentes.

Destarte, o direito das gentes (ius gentium ou inter gentes) já era trabalhado desde o período da Roma Antiga. Contudo, ainda muito pouco especificado, dirigia-se apenas aos estrangeiros, sem uma diferença clara entre o Direito Natural e o direito das gentes. Foi com Suárez que esta noção ganhou um aprofundamento mais robusto.

Para o mestre da Escola de Salamanca, as regras morais são superiores à soberania dos Estados. Em outras palavras: "Se a lei positiva contradiz o direito natural, perdeu sua razão de justiça. É um princípio universal na filosofia política de Francisco de Vitoria"14 (VICENTE, 1952, p. 626). Por isso, afirmava o bem comum universal e a igualdade natural das soberanias, estando elas sob a égide do Direito Natural e do Direito das Gentes. Contudo, cabe ressaltar o fato de que "dizer que a soberania dos estados é relativa e não absoluta significa que o soberano só tem poder para o que é justo e que para o que é injusto nenhum poder tem" (CALAFATE, 2017, p. 52).

Isto posto, Francisco de Vitoria foi um estudioso que se preocupou com as questões mais urgentes de seu tempo. Partiu de uma posição mais profunda sobre o poder civil secular, sobre seu comportamento na organização da comunidade política e sobre a forma de (não) autoridade da Igreja a envolver-se nessas relações.

Assim, as sociedades encontravam fundamento no ius communicationis (lei que vinha da sociabilidade, devido à ordem objetiva do mundo) e ius amisticiae (contrariando a tese hobbesiana de que o homem é o lobo do próprio homem, mas afirmando sua fraternidade), ou

\footnotetext{
${ }^{14}$ Texto original: "si la ley positiva contradice al derecho natural ha perdido su razón de justicia. Es un principio universal en la filosofía política de Francisco de Vitoria".
} 
seja, na humanidade que interliga todos os povos através da razão. Assim, os Direitos Humanos passam a ser considerados não apenas em seus aspectos internos, mas externos.

\section{REFERÊNCIAS}

ANGHIE, Antony. Francisco de Vitoria and the Colonial Origins of International Law. Social \& Legal Studies, [s.1.], vol. 5, no. 3, p. 321-336, Sept. 1996.

ARAUJO, Robert John. Our Debt to de Vitoria: A Catholic Foundation of Human Rights. Ave Maria Law Review, vol. 10, no. 2, p. 313-329, Spring 2012.

CALAFATE, Pedro. A Escola Ibérica da Paz nas universidades de Coimbra e Évora (século XVI). Revista Teocomunicação, v. 44, n. 1, p. 78-96, 2014.

CALAFATE, Pedro. A idea de comunidade universal em Francisco Suárez. IHS - Antiguos Jesuitas en Iberoamérica, v. 5, n. 2, p. 48-65, 2017.

LACAMBRA, Luis Legaz. La Fundamentación del Derecho de Gentes en Suárez. Revista Española de Derecho Internacional, vol. 1, no. 1, p. 11-44, 1948.

TRINDADE, Antônio Augusto Cançado. Tratado de Direito Internacional dos Direitos Humanos. V. I, 2. ed. rev. e atual. Porto Alegre: S. A. Fabris, 2003.

PLANS, Juan Belda. La escuela de Salamanca: la renovación de la teología en el siglo XVI. Madrid: Biblioteca de autores cristianos, 2000.

VICENTE, Luciano Pereña. El concepto del Derecho de Gentes en Francisco de Vitoria. Revista Española de Derecho Internacional, vol. 5, no. 2, p. 603-628, 1952.

\section{DADOS DA PUBLICAÇÃO}

Categoria: artigo de autor convidado.

Recebido em: 23/12/2019.

Aceito em: 24/12/2019. 
